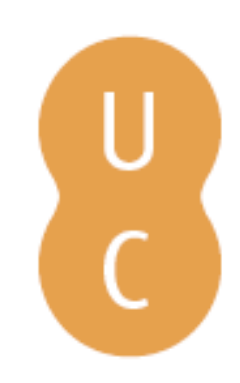

pommalina

\title{
Diáspora e redescoberta das colecções de Alexandre Rodrigues Ferreira
}

Autor(es): $\quad$ Areia, Manuel Laranjeira Rodrigues; Miranda, Maria Arminda; Martins, Maria do Rosário157-

Publicado por: Imprensa da Universidade de Coimbra

URL

persistente:

DOI:

URl:http://hdl.handle.net/10316.2/38447

DOI:http://dx.doi.org/10.14195/978-989-26-0764-1_11

Accessed : $\quad$ 26-Apr-2023 13:23:12

A navegação consulta e descarregamento dos títulos inseridos nas Bibliotecas Digitais UC Digitalis, UC Pombalina e UC Impactum, pressupõem a aceitação plena e sem reservas dos Termos e Condições de Uso destas Bibliotecas Digitais, disponíveis em https://digitalis.uc.pt/pt-pt/termos.

Conforme exposto nos referidos Termos e Condições de Uso, o descarregamento de títulos de acesso restrito requer uma licença válida de autorização devendo o utilizador aceder ao(s) documento(s) a partir de um endereço de IP da instituição detentora da supramencionada licença.

Ao utilizador é apenas permitido o descarregamento para uso pessoal, pelo que o emprego do(s) título(s) descarregado(s) para outro fim, designadamente comercial, carece de autorização do respetivo autor ou editor da obra.

Na medida em que todas as obras da UC Digitalis se encontram protegidas pelo Código do Direito de Autor e Direitos Conexos e demais legislação aplicável, toda a cópia, parcial ou total, deste documento, nos casos em que é legalmente admitida, deverá conter ou fazer-se acompanhar por este aviso.

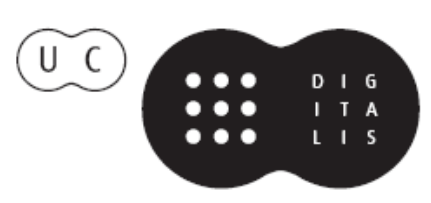


${ }^{1}$ Professor Jubilado do Departamento de Antropologia da Universidade de Coimbra

${ }^{2}$ CIAS - Centro de Investigação em Antropologia e Saúde, Universidade de Coimbra

${ }^{3}$ Museu da Ciência da Universidade de Coimbra

m.areia@netcabo.pt; miranda@antrop.uc.pt; martinsr@antrop.uc.pt

\title{
Diáspora e Redescoberta das Colecçōes de Alexandre Rodrigues Ferreira
}

\author{
Manuel Laranjeira Rodrigues Areia ${ }^{1,2}$, \\ Maria Arminda Miranda ${ }^{2,3}$ e Maria do Rosário Martins ${ }^{2,3}$
}

\footnotetext{
"Viajas para reviver o teu passado? Viajas para achar o teu futuro?

... O viajante reconhece o pouco que é seu, descobrindo o muito que não teve nem terá...”

(Italo CALVINO, As Cidades Invisiveis, 1972)
}

Com recurso a fontes primárias, bibliografia especializada e material de arquivo contemporâneo produzir-se-á um documento ancorado nas seguintes premissas: destacar o decisório vínculo científico entre a Universidade de Coimbra e a Viagem Philosophica; compreender o itinerário museográfico da colecção, especialmente a etnográfica, em articulação com as sucessivas etapas institucionais; analisar a recente dinâmica museológica; perspectivar as vias da contemporaneidade.

A Europa do século XVIII foi marcada por uma sociedade em transformação. Governava-se em defesa da prosperidade económica dos Estados, em nome do bem-estar e das necessidades sociais sob a bandeira do Iluminismo, corrente filosófica pautada pela noção de mutabilidade da natureza e do universo e pela ideia de progresso sendo estas as bases para o entendimento do mundo. Proclamava-se uma revolução intelectual e científica que enfatizava a razão como forma de explicar o universo, a sociedade, o homem e as suas relações com a natureza, valorizando a investigação e a experiência como meios para se atingir o conhecimento e a felicidade. Esta inflexão no pensamento da época é visível nas mais variadas instâncias da produção do conhecimento, inclusive na organização e institucionalização da ciência, mediada por sociedades científicas e pela própria Universidade.

Em Portugal, a corrente de ideias iluministas fomentava a criação de uma nova mentalidade, em parte traduzida pela Reforma da Universidade de Coimbra de 1772, servida por um notável documento orientado pela acção do Reitor D. Francisco de Lemos, Frei Manuel de Cenáculo e Ribeiro Sanches mas, sobretudo, por Luís António Verney através da obra $O$ Verdadeiro Método de Estudar (CORREIA 1954: 6). O teor dos Estatutos que, em Carta de Roboração assinada por D. José em 28 de agosto desse mesmo ano, estabelece a nova criação da Universidade de Coimbra (ESTATUTOS 1972: 5-11), ultrapassou a barreira do tempo sobrevivendo ao declínio da era pombalina, ao 
período conturbado da invasão bonapartista e deslocação da Corte para o Brasil, bem como ao ciclo das lutas liberais, mantendo-se nas suas premissas substanciais até às reformas do Ensino Superior introduzidas durante a Primeira República (MIRANDA et al., 2008: 77).

A Universidade, ao fundamentar as suas propostas pedagógicas nas componentes da observação e da experimentação inevitavelmente impulsionaria a constituição das estruturas indispensáveis à sua execução. Nesta conjuntura se regista o vínculo de Domingos Vandelli ao ser designado por Pombal para integrar a criação da Faculdade de Filosofia e como lente de Química e História Natural competindo-lhe, por inerência de funções, a organização e a direcção do Gabinete de História Natural. Neste sentido representa o ponto de partida quanto à soma de conhecimentos científicos e metodológicos subjacentes às expedições efectuadas pelos seus discípulos ${ }^{1}$.

Por outro lado, o apoio do Estado garantirá que a ciência seja difundida com mais facilidade sendo que os naturalistas eram "recrutados" da Universidade para a Corte atendendo aos interesses dos governantes ${ }^{2}$.

Neste período de profundas transformações se desenvolveu o percurso académico de Alexandre Rodrigues Ferreira ${ }^{3}$, ingressando em 1774 na Faculdade de Filosofia onde obteve o grau de doutor dado por Domingos Vandelli a 10 de Janeiro de 1779 (LIMA 1954: 77-78).

A 31 de agosto de 1783 inicia-se uma das mais importantes expedições de carácter multidisciplinar, inequivocamente planeada para a colónia brasileira, empreendida sob a tutela do poder político português e inscrita nos cânones científicos da Universidade de Coimbra.

Alexandre Rodrigues Ferreira assessorado por José Joaquim Freire, Joaquim José Codina ("riscadores") e Agostinho Joaquim do Cabo (jardineiro botânico) trilhou, durante quase dez anos, as Capitanias do Grão-Pará, Rio Negro, Mato Grosso e Cuyabá, num périplo de 39.000 quilómetros (Lima, 1953: 15). Actuou no cumprimento de missôes geoestratégicas, burocráticas, economicistas mas, também, numa perspectiva que registava a descrição exacta das espécies em nome de uma visão centralizadora da ciência. Destacou-se tanto pela formação académica como pela prática profissional projectada nos seus escritos e na recolha de um vastíssimo espólio durante a Viagem Philosophica. Representa para a Antropologia um ponto de chegada traduzido no ingresso de centenas de artefactos, reduzida representação do seu grandioso trabalho.

1 “...Tenho feito todas as deligências para completar o plano da expedição dos naturalistas e remetê-lo a V. $\mathrm{Ex}^{\mathrm{a}}$... agora presento a V. Exa. o rol dos instrumentos e outras coisas necessárias à viagem dos naturalistas para executar as instruçôes que tiveram e assim formar com a maior diligência possível huma exata história natural de tão vasto continente..." (Carta de Domingos Vandelli a Martinho de Mello e Castro. 1778. Documento manuscrito, maço 26, Reino, Arquivo Histórico Ultramarino).

2 "... Os ditos Naturalista, e Riscadores, devem empregarse debaixo das ordens de V.S. ${ }^{a}$, em examinar, e descrever tudo o que houver nesse Estado relativo á Historia natural; e em recolher, e preparar o que se deve remetter a esta Corte, na conformidade das Instruçoens que leva o dito Alex. ${ }^{e}$ Roiz, debaixo de cuja Inspeção devem trabalhar os outros tres, que vão na sua companhia..." (Carta de Mello e Castro a Martinho de Sousa e Albuquerque, Governador do Pará: Lima, 1953: pp. 11).

${ }^{3}$ Nasceu na Bahia, Brasil, a 1756 e faleceu em Lisboa em 1815. Matriculou-se pela primeira vez na Universidade de Coimbra em 1770 em Instituta. Em 1780 tornou-se membro correspondente da Real Academia das Ciências e trabalhou como naturalista no Real Museu da Ajuda entre 1778-1783 (MARTINS et al., 2010: 242). 


\section{COMPREENDER A VIAGEM}

A partir de 1781, os diversos colectores naturalistas formados em Coimbra ou os funcionários da administração colonial passaram a dispor de normas emanadas pela Academia das Ciências sobre o modo de recolher os produtos de História Natural, nos quais se incluíam a cultura material das populações com que entravam em contacto. Um Museu de História Natural só estava completo se tivesse os vestidos, ornamentos, armas e outras manufacturas das nações mais desconhecidas de forma a conhecer a sua indústria (PEREIRA 2005: 55).

Com efeito as expedições realizavam-se baseadas nas Breves Instruções da Academia das Ciências orientadoras de uma perspectiva omnipresente da ciência, instrumentos de controlo essenciais para a produção do conhecimento: determinavam o que levar na bagagem; forneciam indicações básicas que norteavam a maneira de produzir as observações etnográficas e elaborar Memórias, Participações e Relações; incluíam regras minuciosas quanto à forma de desenhar com objectividade os modelos humanos e os exemplares dos três reinos da natureza, até então desconhecidos; designavam quais os produtos naturais e industriais a serem recolhidos e como deviam ser preparados; apontavam os locais a serem percorridos (MIRANDA et al., 2008: 68).

A Viagem Philosophica (1783-1792) tinha sido conjecturada num cenário de interesses políticos e económicos do poder central, apoiada pelo saber da Universidade. Estruturada desde 1778, previa o esforço de naturalistas e matemáticos tecnicamente apetrechados para o território de pesquisa e auspiciosa fonte de desejadas riquezas, cuja amplitude é evidenciada no rigor dos registos escritos e nas representações executadas a aguarela e pelo envio de milhares de espécies e de artefactos.

Os riscadores produziram um vasto material iconográfico que caracterizava tanto o ambiente geográfico, animais, plantas, como exemplares da cultura material. Porém, a representação do índio enquanto ser humano não foi além de escassos apontamentos retratados com breves descrições referentes às comunidades identitárias a que pertenciam. Culturas bizarras para uns, cientificamente identificadas por outros, os índios eram avaliados e distinguidos etnicamente consoante a sua aparência, atavios, tatuagens ou outras alterações de carácter intencional; reconhecidos pelas suas capacidades técnicas e estado "civilizacional" (caso de relatos efectuados por Ferreira em várias Memórias) ou analisados pela falta de aptidões, relacionamento com o meio e com as diversas etnias que os rodeavam.

\section{DiÁSPORA DAS COLECÇÕES}

O Real Museu de História Natural da Ajuda recebeu, durante o período que durou a expedição, dezanove remessas de Productos Naturaes dos trez Reinos, Animal, Vegetal e Mineral além das Curiosidades artificiais dos Gentios e Indios domesticados [ao serviço doméstico].

As colecções recolhidas por Ferreira conheceram, ao longo do tempo, vários destinos: Museu de História Natural de Coimbra, Museu de História Natural de 
Paris, Academia das Ciências de Lisboa, Museu Bocage, Brasil ${ }^{4}$ e Madrid. Em cumprimento de um acordo estabelecido desde 1801 foi transferido do Museu da Ajuda para o Museu de História Natural da Universidade de Coimbra um importantíssimo acervo detalhado na Relação Dos Produtos naturais e industriaes que deste Real Museu se remetterão para a Universidade de Coimbra em 1806 (figuras $1 \mathrm{~A}$ e $1 \mathrm{~B})$.
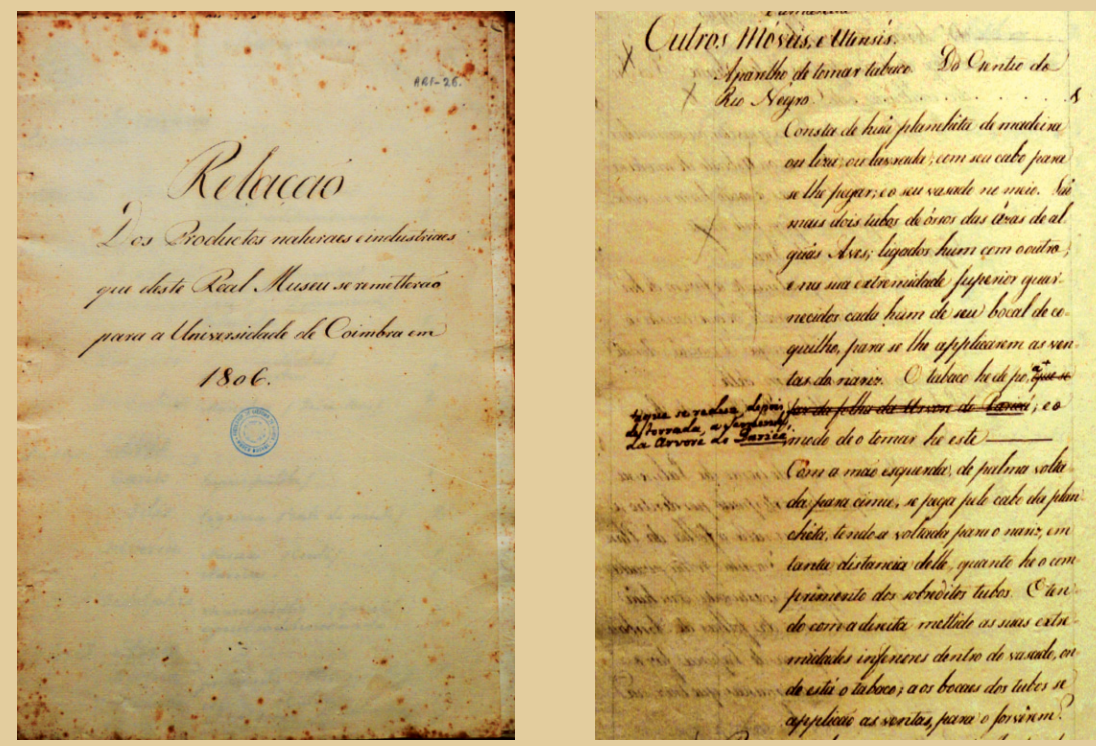

Figuras. 1A e 1B. - Documento manuscrito pertencente ao Museu Bocage de Lisboa.

Trata-se de uma listagem sistemática que, relativamente aos designados Produtos industriaes (nem todos oriundos do Brasil), menciona o envio de mais de quatro centenas de artefactos com a informação organizada em torno das categorias funcionais. Indica, quase sempre e com precisão, o local de proveniência, materiais, particulares aspectos da confecção e o correspondente número de exemplares, por vezes com anotaçōes feitas pelo punho de Ferreira (figura 1B).

É justo acentuar o esforço, o pormenor e a competência que Rodrigues Ferreira dedicou às inúmeras Memórias, possibilitando aos futuros investigadores de gabinete perceber o funcionamento e o enquadramento de alguns dos artefactos recolhidos. Destacamos a Memória sobre A louça que fazem as indias do Estado [Barcelos], onde descreve minuciosamente todo o processo de fabrico artesanal: $o$ barro mais limpo de areia é o que elas mais preferem: sem rodas, nem máquinas empreendem à mão a tal fábrica de panelas, pratos... (FERREIRA, 2005: 75) (figuras 2 e 3$)$.

4 "When the Court moved to Brazil (1808) Dom João, the prince regent, took important collections with him. When he became king he ordered that items should be sent to the museum in Rio de Janeiro, which he had founded" (AREIA; MIRANDA, 1995: 69). 


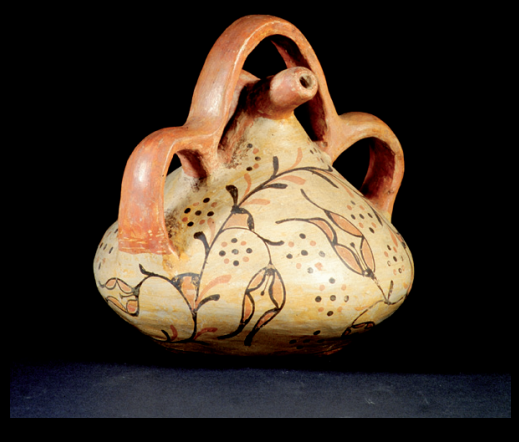

Figura 2. Bilha. Índias de Belém? ANT.Br.45. Alt. $25 \mathrm{~cm}$. MCUC

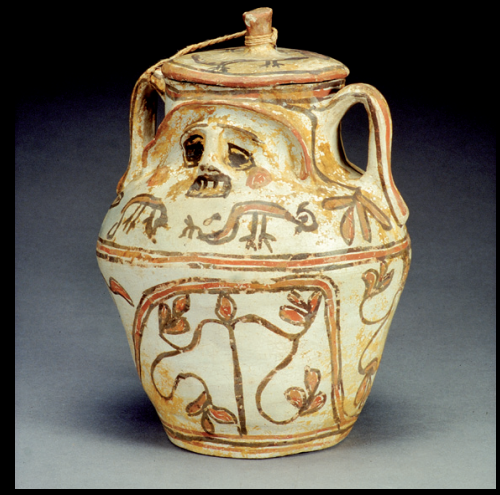

Figura 3 Vaso com asas. Índias de Barcelos?

ANT.Br.42. Alt. 22cm. MCUC

\section{REDESCOBRIR AS COLECÇÔES}

Um longo período de relativo esquecimento desta colecção foi interrompido com o início da investigação sistemática da cultura material realizada por Thekla Hartmann, então professora na Universidade de S. Paulo. O reconhecimento, em 1981, de uma das máscaras representada numa aguarela executada por Codina (Figura 4), já tratada pela própria em 1975 numa perspectiva etnográfica, provocaria a renovada atenção sobre as peças originárias do Brasil registadas nos Inventários antigos do Museu Antropológico (figura 5). A importante informação resgatada daqueles documentos a par da dos manuscritos existentes no Museu Bocage pretextaria repensar a recolha efectuada por Rodrigues Ferreira bem como o espólio existente na Universidade de Coimbra $^{5}$ (figuras 6 e 7 ).

Este inédito e importante material foi responsável, em 1986, pela preparação de um projecto, não concretizado, que reuniria os quatro grandes grupos contidos na Relação de 1806: Antropologia, Botânica, Mineralogia e Zoologia, traçando o "perfil do naturalista".

\footnotetext{
${ }^{5}$ Nos Inventários antigos $(1829,1850$ e 1881) os espécimes foram descritos de diversas formas aludindo muitas vezes a conjuntos de objetos. Noutros casos foram etiquetados erradamente, caso das pranchetas para paricá, catalogadas como "Moldura que parece ter sido feita para se lhe collocar um pequeno espelho ao centro" (figura 7).
} 


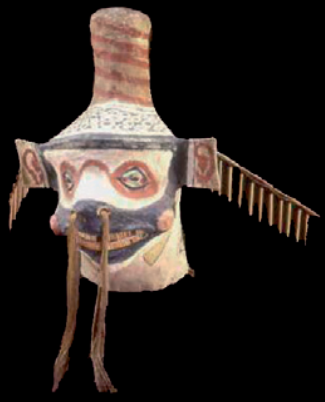

Figura 4 - Máscara. Índios Jurupixuna. ANT.Br.136. Alt. 61,5 cm. MCUC.

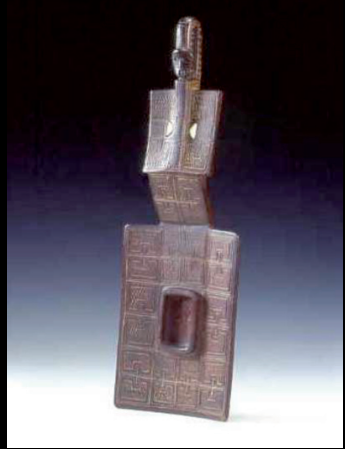

Figura 6 - Prancheta para paricá. Índios Maué.

ANT.Br.37. Alt. $45 \mathrm{~cm}$. MCUC

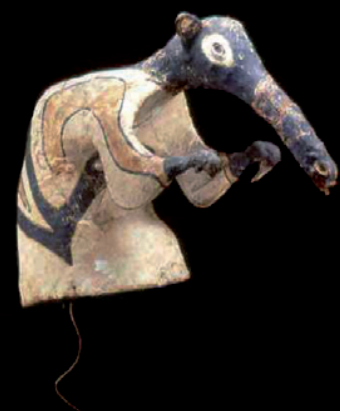

Figura 5 - Máscara. Índios Jurupixuna. ANT.Br. 137. Alt. 31,5 cm. MCUC

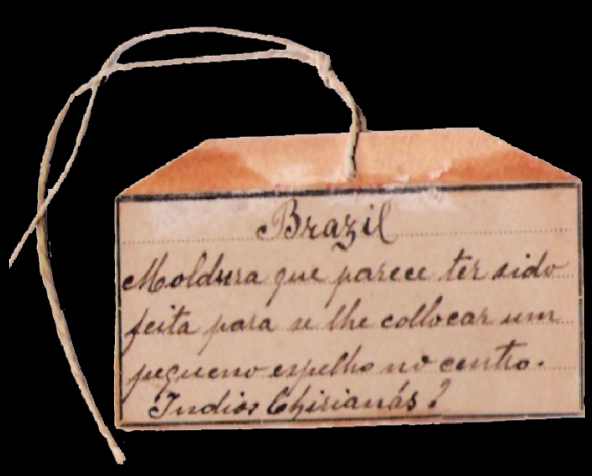

Figura 7 - Etiqueta identificativa da prancheta para paricá. Inícios do século XIX?. MCUC

Em 1991, o Museu Antropológico exibe pela primeira vez, após 200 anos da realização da Viagem grande parte do espólio etnográfico conservado em Portugal na exposição Memória da Amazónia (AREIA et al., 1991). Este acervo tem integrado várias iniciativas, quer no país ${ }^{6}$ (figuras 8 e 9) quer no estrangeiro ${ }^{7}$, itinerância que

${ }^{6}$ 1991, Coimbra, Museu Antropológico da Universidade de Coimbra.

1992, Lisboa, Mosteiro dos Jerónimos.

1992, Lisboa, Museu Nacional de Etnologia.

1992, Figueira da Foz, Museu Municipal Dr. Santos Rocha.

1994, Porto, Alfândega do Porto.

1995, Lisboa, Centro Cultural de Belém.

2000, Coimbra, Museu Zoológico da Universidade de Coimbra.

2000/2001, Lisboa, Museu Nacional de Etnologia.

2007, Coimbra, Museu Antropológico da Universidade de Coimbra.

2007/2008, Coimbra, Museu Botânico da Universidade de Coimbra.

2008, Coimbra, Escola Superior de Educação de Coimbra.

${ }^{7}$ 1997, Manaus, Centro Cultural Palácio Rio Negro. 
se traduziu em novos modelos expositivos articulados com diferentes abordagens, estudos e perspectivas antropológicas. Desde então reinterpretaçóes disciplinares enriqueceram o debate e deram continuidade à multiplicidade de questôes levantadas em torno do extenso legado de Rodrigues Ferreira.

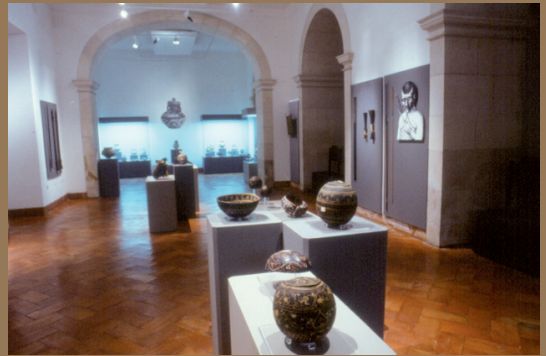

Figura 8 - Exposição Memória da Amazónia.

MAUC. Coimbra. 1991.

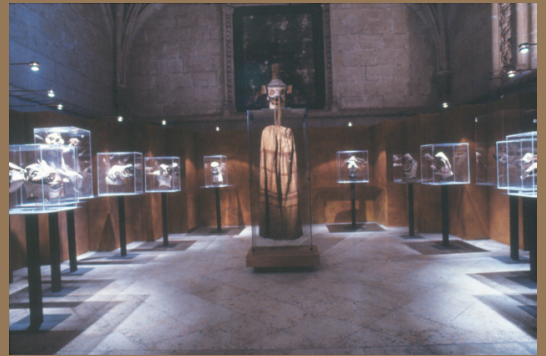

Figura 9 - Exposição Memória da Amazónia.

Mosteiro dos Jerónimos, Lisboa. 1992.

A par dos artefactos colectados no século XVIII (Figura 10), as colecçôes de Antropologia foram valorizadas com a aquisiçãa de materiais de concepção recente (Figura 11), produçôes oriundas das mesmas áreas culturais da Amazónia percorrida por Ferreira, reveladoras de um minucioso e complexo conhecimento empírico do meio ambiente, potenciado por um não menos complexo pensamento filosófico específico das sociedades em questão (Dias, 1994: 45).

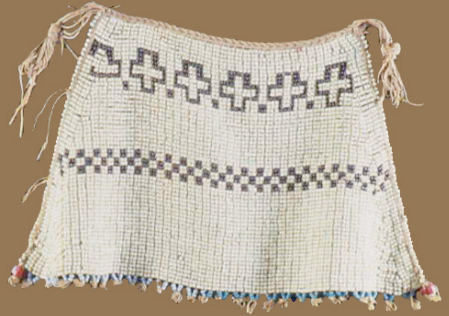

Figura 10. Tanga. Índios Wapixana? ANT.Br.90. Alt. $9 \mathrm{~cm}$. MCUC

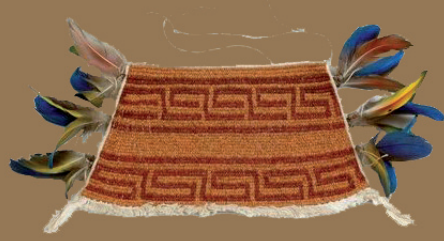

Figura 11. Tanga. Índios Way-Way. ANT.D.94.1.31. Alt. $22.5 \mathrm{~cm}$. MCUC

2000, S. Paulo, Associação Brasil 500 Anos de Artes Visuais, Parque Ibirapuera.

2000/2001, Rio de Janeiro, Museu de Arte Moderna.

2001/2002, Londres, British Museum.

2005, Paris, Galeries Nationales du Grand Palais.

2005/2006, Madrid, Centro Cultural del Conde Duque.

2006/2007, Paris, Musée du quai Branly.

2008/2009, Rio de Janeiro, Museu Nacional do Rio de Janeiro.

2011/2012, Bruxelas, ING Cultural Space. 


\section{Perspetivar as Vias Da CONTEMPORAneidade}

A contemporaneidade e representatividade destes artefactos exemplificam a continuidade (também a interrupção) da memória social e colectiva ressaltando a ideia de herança cultural perceptível durante séculos de interacção indígena e europeia; abrem caminho à compreensão do uso de materiais, estruturas, funções e significados enquanto modelos culturais de sociedades em mutação reforçando e promovendo novas investigaçóes na área da antropologia. Aparentemente estranhos ou inclassificáveis, a visão dos objectos é alterada de acordo com as perspectivas em que são observados (KAEPPLER, 2006: 130).

Corroborando LE FUR (2006: 233), aquilo que superficialmente poderá parecer hoje de menor interesse questiona a relatividade dos olhares entre o período setecentista e os nossos dias, tanto mais que razões explicáveis pela formação e conjuntura científica associadas a estratégias políticas e economicistas e, porventura, a motivações de carácter estético, determinaram a escolha e a colecta dos objectos.

A conservação e divulgação do património, antigo ou contemporâneo, material ou imaterial, só poderão ser efectivadas se estudado e inventariado, primeiro procedimento, incontornável, e aquele que permitirá alicerçar a divulgação do conhecimento com recurso às tecnologias de informação.

Partindo do alargamento do conceito clássico da museologia, insubstituível enquanto discurso de proximidade científica e afectivamente enriquecedor, para conteúdos museológicos virtuais, será desejável a produção de aplicações multimédia que ofereçam a possibilidade de interacção com os objectos, a obtenção de informações técnicas, culturais e históricas e estabeleçam o diálogo entre os diversos intervenientes potenciando a acessibilidade a conjuntos particularmente perecíveis. Esta será uma das formas de veicular práticas informativas, operar a divulgação de experiências multidisciplinares e contribuir para a transversalidade de olhares perspectivados por renovados enfoques interpretativos, em tempos e espaços diferenciados. Estão neste caso, por questôes que se prendem com a fragilidade da preservação e raridade dos artefactos, o núcleo das máscaras (figuras 12A e 12B; figuras 13A e 13B) e da plumária (figuras 14 e 15) do século XVIII que só poderá ser visitável no Museu da Ciência da Universidade de Coimbra.

Destacamos a importância de, em torno desta inesgotável temática, se construírem originais interpretações disciplinares conducentes a práticas de mediação cultural verdadeiramente isentas e transparentes que tenham por desígnio a acessibilidade de todos os públicos aos museus, vincando a atenção devida aos visitantes com necessidades especiais, intelectuais, físicas ou sociais.

O extenso legado etnográfico resultante da Viagem Philosophica constitui, ainda hoje, um notável instrumento de estudo sobre realidades distantes mas, também, uma ferramenta de percepção sobre a propriedade cultural das comunidades de origem ou suas sucedâneas. Contudo, os dados consequentes das circunstâncias históricas e pessoais associadas à recolha nem sempre franqueiam as respostas almejadas. Percorremos, todos quantos sentimos o desafio de procurar compreender aquelas culturas em permanente transformação, um campo de trabalho talvez nunca concluído. Por isso, em homenagem aos Povos Descendentes daqueles que foram os autores e participantes das histórias de vida que se cruzaram com a de Alexandre 
Rodrigues Ferreira e seus companheiros, numa das mais importantes Missōes científicas empreendidas no século XVIII, auguramos que outras pesquisas venham enriquecer o debate. Indagando o papel dos museus, dos acervos e da sua solidez epistemológica consideramos fundamental a participação daquelas comunidades na reanálise e futura reinterpretação das colecçôes.
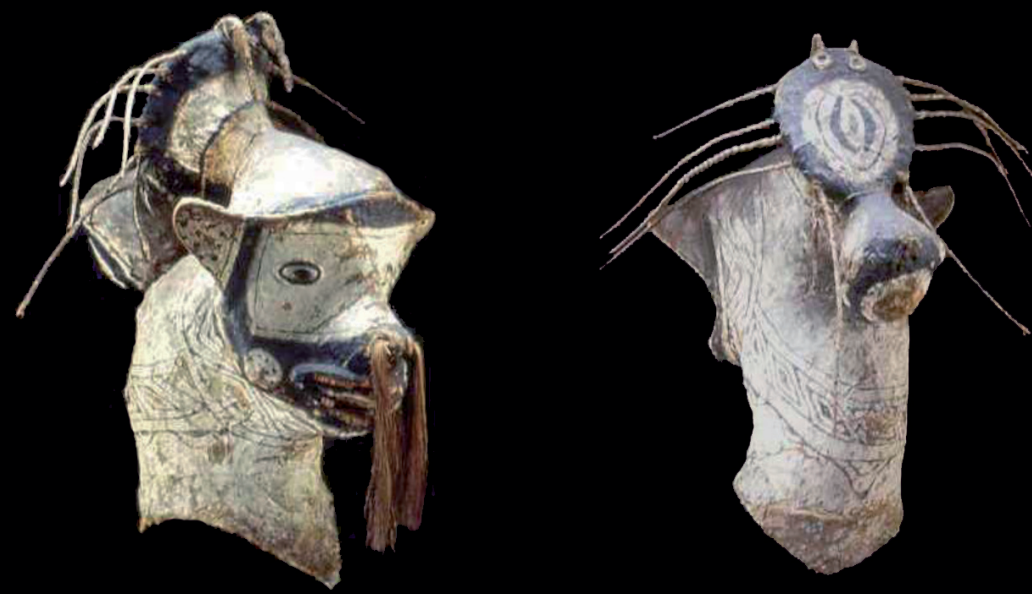

Figuras 12A e 12B - Máscara bicéfala. Índios Jurupixuna. ANT.Br.138. Alt. 52cm. MCUC.
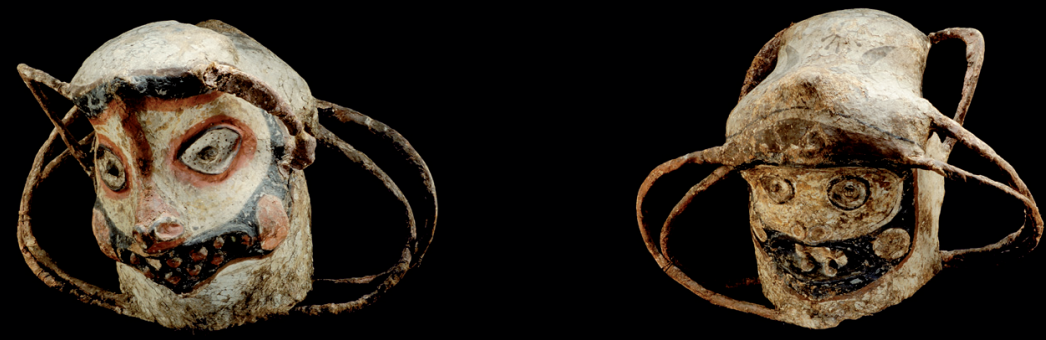

Figuras 13A e 13B - Máscara bicéfala. Índios Jurupixuna. ANT.Br.144. Alt. 37cm. MCUC 


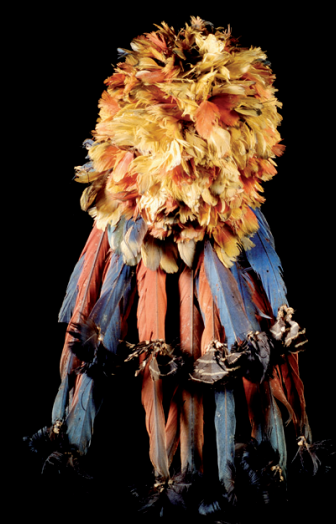

Figura 14. Coifa. Índios Munduruku. ANT.Br.168. Alt. 49 cm. MCUC

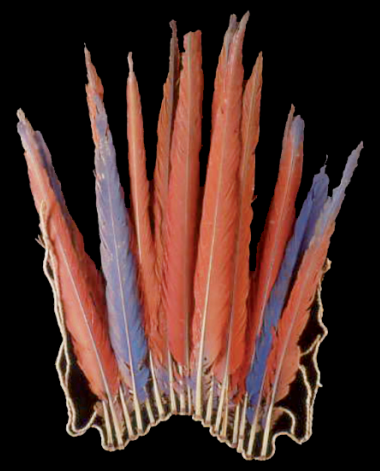

Figura 15. Diadema. Índios Munduruku? ANT.Br.156. Alt. 53 cm. MCUC. 


\section{CRÉDITOS FOTOGRÁFICOS}

Carlos Barata, Figuras 2, 3, 4, 5, 6, 7, 8, 9, 10, 12, 13, 14 e 15

António Moreira Pires, Figura 11

\section{REFERÊNCIAS}

AREIA, Manuel L. R. de; MIRANDA, Maria A.; HARTMANN, Thekla - Memória da Amazónia. Coimbra, Museu e Laboratório Antropológico da Universidade de Coimbra, 1991.

AREIA, Manuel L. R. de; MIRANDA, Maria A. - A philosophical journey to the Amazon, 1783-92: The story of the gathering and dispersal of a collection. Journal of the History of Collection Oxford: Oxford University Press. Vol. 7 no 1 (1995). p. 59-71.

ARQUIVO HISTÓRICO ULTRAMARINO. Carta de Domingos Vandelli dirigida a Martinho de Mello e Castro. [Documento manuscrito], maço 26, Reino. 1778.

CORREIA, Maximino - A Reforma Pombalina da Universidade de Coimbra e os Italianos. Estudos Italianos em Portugal. Lisboa, Instituto Italiano di Cultura in Portogallo. n. 13 (1954), p. 3 -25.

DIAS, José A. F. - Revista Memória da Amazónia, Etnicidade e Territorialidade. Porto: Universidade do Porto.

FERREIRA, Alexandre Rodrigues, Universidade do Amazonas - Memória sobre a louça que fazem as índias do Estado. In Soares, J. M.; Ferrão, C., coord. Viagem ao Brasil de Alexandre Rodrigues Ferreira. Colecção Etnográfica. Lisboa: Kapa Editorial, 2005. Vol. 3, p. 75.

KAEPPLER, Adrienne L. Destins - singuliers d'objets. In LE FUR, Yves, dir. D'Un Regard L'Autre. Histoire des regards européens sur l'Afrique, l'Amérique et l'Océanie. Paris: Musée du quai Branly, 2006, p. 130-131.

LE FUR, Yves, dir. - D’Un Regard L'Autre. Histoire des regards européens sur l'Afrique, l'Amérique et l'Océanie. Paris: Musée du quai Branly, 2006.

LIMA, Américo P. de - O Doutor Alexandre Rodrigues Ferreira. Lisboa: Agência Geral do Ultramar, Divisão de Publicações e Biblioteca, 1953.

LIMA, Américo P. de - As Matrículas do Doutor Alexandre Rodrigues Ferreira. Boletim da Sociedade Broteriana. Coimbra: Instituto Botânico da Universidade de Coimbra. Vol. 27 (1954), p. 77-80. 2a série.

MARTINS, Maria do Rosário; SANTOS, Ana Luísa; MIRANDA, Maria Arminda; MATOS, Victor - Body modification and paleopathological evidence in the iconography from the 'Philosophical Travel' to Brazilian Amazonia' by Alexandre R. Ferreira (1783-1792). Antropologia Portuguesa. Coimbra: n. ${ }^{\circ}$ 26-27 (2009/2010), p. 239-257.

MIRANDA, Maria Arminda; MARTINS, Maria do Rosário; AREIA, Manuel Rodrigues - Porque antes de se saber o uso e préstimo das coisas é necessário conhecê-las. In BERNASCHINA, Paulo, ed. Gabinete Transnatural de Domingos Vandelli. Porto: Artez, 2008. p. 67-79.

PEREIRA, Manuela - O Museu Etnográfico da Sociedade de Geografia de Lisboa: modernidade, colonização e alteridade. Lisboa. Fundação Calouste Gulbenkian, 2005. Fundação para a Ciência e Tecnologia.

UNIVERSIDADE DE COIMBRA - Estatutos da Universidade de Coimbra: (1772). Coimbra: Universidade de Coimbra, 1972. 